\title{
(C) OPEN ACCESS \\ Injury-related mortality among children younger than 5 years in China during 2009-2016: an analysis from national surveillance system
}

\author{
Liangcheng Xiang, ${ }^{1}$ Ke Wang, ${ }^{1}$ Lei Miao, ${ }^{1}$ Leni Kang, ${ }^{1}$ Xiaohong Li, ${ }^{1}$ Jun Zhu, ${ }^{1,2}$ \\ Juan Liang, ${ }^{1}$ Qi Li, ${ }^{1}$ Chunhua He, ${ }^{1,3}$ Yanping Wang ${ }^{1,2}$
}

${ }^{1}$ National Office for Maternal and Child Health Surveillance of China, West China Second University Hospital, Sichuan University, Chengdu, China ${ }^{2}$ Key Laboratory of Birth Defects and Related Diseases of Women and Children (Sichuan University), Ministry of Education, Chengdu, China ${ }^{3}$ Department of Pediatrics, West China Second University Hospital, Sichuan University, Chengdu, China

\section{Correspondence to}

Chunhua He, National Office for Maternal and Child Health Surveillance of China, West China Second University Hospital, Sichuan 610041, China; yanpingwang0618@ 163.com

Professor Yanping Wang, National Office for Maternal and Child Health Surveillance of China, West China

Second University Hospital, Sichuan 610041, China; yanpingwang0618@163.com

$L X$ and $K W$ contributed equally.

Received 26 April 2018 Revised 30 June 2018 Accepted 3 August 2018 Published Online First 19 December 2018
ABSTRACT

Background Epidemiology in injury-related mortality among children younger than 5 years was unreported in China recently.

Methods Data were obtained from China's Under 5 Child Mortality Surveillance System (U5CMSS) in 20092016. Injury-related mortality rates were calculated by residence, age-group, gender and major injury type (drowning, traffic injuries, suffocation, poisoning, falls). The average annual decline rate (AADR) was calculated based on the annual mortality rates by Poisson regression and the relative risk (RR) between urban and rural residence was examined based on the rates of two years for each time point by Cochran-Mantel-Haenszel method.

Results U5CMSS contained 6503 injury-related deaths of children younger than 5 years during the study period, of which $58.6 \%$ were male, $86.0 \%$ occurred in rural areas, $65.7 \%$ were children aged 12-59 months. Deaths were mainly attributed to suffocation (34.3\%), drowning (29.6\%), traffic injuries (17.7\%), falls $(7.2 \%)$ or poisoning $(4.7 \%)$. The injury-related mortality rate dropped from 274.7 to 189.2 per 100000 live births from 2009 to 2016 , giving an AADR of $4.53 \%(95 \% \mathrm{Cl}$ $3.50 \%$ to $5.55 \%$ ). During 2009-2016, the injury-related mortality rate in rural area was higher than that in urban area, the adjusted RRs (aRRs) in infants and children aged 12-59 months were 3.32-6.04 and 4.31-5.49, respectively.

Conclusion The rate of injury-related deaths in children younger than 5 years has decreased in China, but it remains high and strong urban-rural disparities still exist. Public health programmes and policy interventions should focus particularly on suffocation among infants and on drowning and traffic injuries among children aged 12-59 months, especially in rural areas.

\section{INTRODUCTION}

Injuries are estimated to have caused 32600 deaths among children aged 1-59 months around the world in $2015 .^{1}$ These deaths have an immeasurable impact on family and society, especially in low-income and middle-income countries, where the rates of mortality related to injury among infants and children aged 12-59 months are 3.7 and 5.8 times higher than those in high-income countries, respectively. ${ }^{2}$ This has led a growing number of governments in developed and developing countries to focus on reducing such deaths. In 2013, China, one of the largest developing countries, ranked fifth in the number of all-cause deaths in children younger than 5 years, falling behind India, Nigeria, Pakistan and the Democratic Republic of the Congo. ${ }^{3}$ One report estimates that $14.6 \%$ of deaths in children younger than 5 years in China are due to injuries, ${ }^{4}$ making such injuries the third leading cause of mortality among this age group in 2015 .

Approximately $90 \%$ of injuries are not random events and so can be prevented and controlled. ${ }^{5}$ China released the 'Healthy China 2030 Planning Outline' in 2016 with a goal of establishing a comprehensive injury monitoring system and developing guidelines and standards for strengthening the prevention and intervention of injuries, reducing traffic injuries and drowning and preventing poisoning. ${ }^{6}$ These efforts require accurate, detailed knowledge of the epidemiology of common injuries and injury-related deaths. ${ }^{7-10}$ There were some publications ${ }^{11-17}$ that have provided insights into children's injury-related mortality. However, those were either major certain specific injuries such as drowning or poisoning or mostly from before 2010. No recent and comprehensive studies have been found, leaving a nearly decade-long gap in our understanding of the state of injury prevention in China. The rapid economic changes and increasing relevance of urban-rural disparities in the country highlight the need for a current understanding of injury-related deaths in children. ${ }^{18}$

Therefore, we investigated the epidemiology of injury-related mortality in children younger than 5 years in China using Under 5 Child Mortality Surveillance System (U5CMSS) data for the period 2009-2016. Our hope is that our study will provide some information for the development of timely and effective child injury intervention programme to reduce injury-related deaths.

\section{METHODS}

\section{Data source}

This study used data from the U5CMSS, a population-based surveillance system for monitoring the death of children younger than 5 years. The U5CMSS covered a total population of approximately 44-47 million individuals across 334 representative districts/counties, of which 124 are urban and 210 are rural, in 31 provinces in mainland China. ${ }^{4} 19$ It follows stringent procedures for data collection, reporting, auditing and quality control, helping to reduce the risk of under-reporting. These data were collected and reported by experienced 
doctors and checked for quality and accuracy at the county level by paediatric healthcare institutions and individuals. Details about data collection ${ }^{20}$ and data quality control ${ }^{22}$ have been described previously. Children's death reports included demographic characteristics such as gender, age, primary cause of death, location of death and other key information. According to the WHO International Classification of Diseases (Tenth Revision, ICD-10), ${ }^{23}$ injuries in this study were classified into six types: drowning (W65-74), traffic injury (V01-V09, V30-V89, V98-V99), suffocation (W75-W76, W78-W80, W83-W84), poisoning (X40-X49), fall (W00-W19) or 'other' (V01-Y98, excluding the above-mentioned codes).

\section{Statistical analysis}

Children were stratified into two age groups of $0-11$ or $12-59$ months, since injury risks depend on developmental milestones and stages of growth. ${ }^{24}$ For example, infants cannot yet walk, so their injuries are due largely to parental negligence or abuse, whereas children aged 12-59 months are hyperactive, curious and exploratory, leading them to cause many of their own injuries. ${ }^{26}$ In addition to calculating injury-related mortality across the entire study period of 2009-2016, results were also calculated in 2-year intervals to obtain robust estimation.

Annual numbers of injury-related deaths and live births were adjusted by a 3 -year moving average under-reporting rate based on annual national data quality control results. The national rate was adjusted by the ratio of urban to rural population based on the national censuses in 2000, when the urban:rural ratio was $1: 4$, and in 2010, when the ratio was $1: 2.33$.

Average annual decline rate (AADR) and 95\% CIs were calculated by Poisson regression. AADR was calculated using the equation

$$
\begin{gathered}
\log (\text { Deaths })=\log (\text { Live births })+\alpha+\beta_{1}{ }^{*}(\text { Year })+\beta_{2}{ }^{*} \text { Residen- } \\
c y+\beta_{3}{ }^{*} \text { Gender }+\beta_{4}{ }^{*} \text { Year }{ }^{*} \text { Residency }+\in
\end{gathered}
$$

where Deaths refer to the number of deaths due to injury during the year specified by Year (between 2009 and 2016), Live births refer to the annual number of live births during the specified Year, $\alpha$ is a constant term and $\in$ is a residual term. Residency can be urban or rural, while Gender can be male or female.

The rate of mortality due to injury was defined as the number of injury-related deaths per 100000 live births. Trends in the proportion of all-cause deaths due to injury during 2009-2016 were assessed for significance using the $\chi^{2}$ trend test. The adjusted relative risk (aRR) and 95\% CI were calculated using the Cochran-Mantel-Haenszel method. These parameters were calculated separately for males or females, for children in urban or rural areas and for specific types of injury.

All statistical analyses in this study were performed using SAS V9.4 (SAS Institute, Cary, North Carolina, USA).

\section{RESULTS}

\section{Epidemiology of mortality due to injury among children younger than 5 years}

A total of 3299741 live births and 6503 injury-related deaths were registered in U5CMSS from 2009 to 2016. Of the 6503 deaths, $58.6 \%$ were boys and $41.4 \%$ were girls, $14.0 \%$ occurred in urban areas and $86.0 \%$ occurred in rural areas, $34.3 \%$ were infants and $65.7 \%$ were children aged $12-59$ months. The causes of death were drowning (29.6\%), traffic injuries (17.7\%), suffocation (34.3\%), poisoning (4.7\%), falls (7.2\%) and 'other' causes $(6.4 \%$, including 77 cases of burns/scalds).

\section{Trends in injury-related mortality rates among children younger than 5 years}

The rate of injury-related mortality dropped from 274.7 per 100000 live births in 2009 to 189.2 in 2016, corresponding to an AADR of $4.53 \%$ (95\% CI $3.50 \%$ to $5.55 \%$; figure 1 ). The proportion of injury-related deaths to all-cause deaths showed an increasing trend, but this did not achieve significance $(Z=0.828$, $\mathrm{p}=0.408)$.

From 2009 to 2016, in urban areas, the mortality rates decreased from 67.2 to 56.4 per 100000 live births, giving an AADR of $1.58 \%$ (95\% CI -1.28 to $4.36 \%$; figure 2 ). In rural areas, the mortality rates decreased from 359.2 to 248.5 per 100 000 live births, giving an AADR of $4.62 \%$ (95\% CI $3.90 \%$ to $6.11 \%$; figure 3 ).

\section{Injury-related mortality rates among children stratified by age, gender and urban/rural residence}

Similar mortality rates among infants were observed between boys and girls in urban and rural areas. After adjusting for gender, the aRR of injury-related mortality rate in rural areas ranged from 3.32 to 6.04 relative to urban areas (table 1 ).

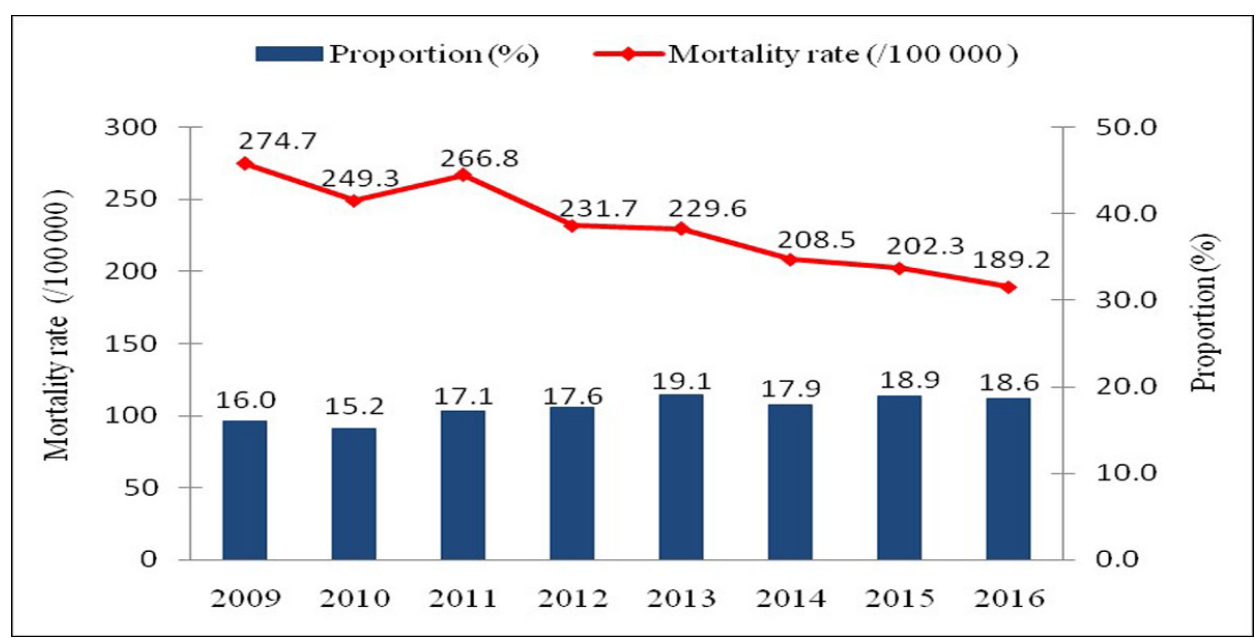

Figure 1 Mortality rate due to injury in children younger than 5 years in China (urban and rural areas combined), and the proportion of injuryrelated deaths to all-cause deaths, 2009-2016. 


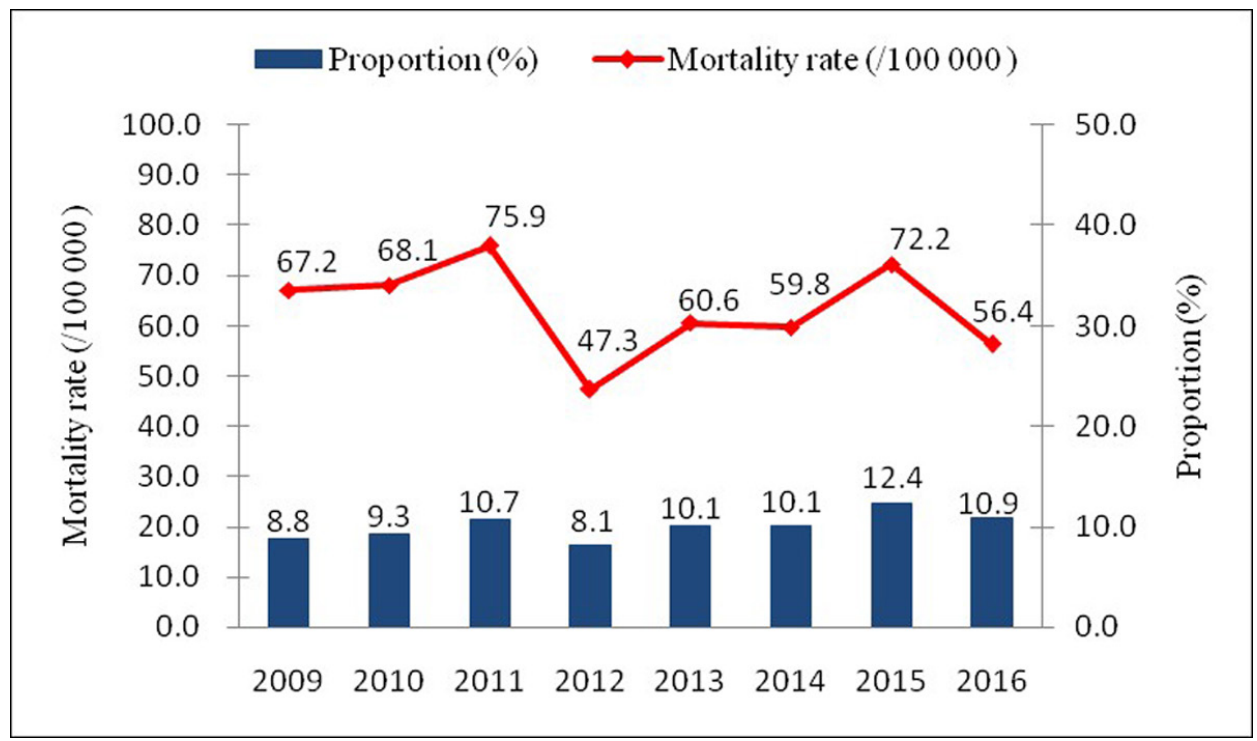

Figure 2 Mortality rate due to injury in children younger than 5 years in urban areas in China, and the proportion of injury-related deaths to allcause deaths, 2009-2016.

In urban areas, no statistically significant changes in mortality rates among children aged 12-59 months were observed, except in 2011-2012. In rural areas, in contrast, mortality rates were significantly higher in boys than girls $(\mathrm{p}<0.05)$. After adjusting for gender, the aRR of injury-related mortality rate in rural areas ranged from 4.31 to 5.49 relative to urban areas (table 2).

\section{Mortality rates in urban or rural environments due to different types of injury}

Among infants, too few deaths occurred as a result of drowning, traffic injuries, poisoning or falls to allow calculation of AADR and aRR between urban and rural areas, but these parameters could be calculated for deaths due to suffocation, which accounted for $83.0 \%$ of all injury-related deaths. During 20092016, the mortality rate was 66.0 per 100000 live births, the AADR was $2.62 \%(95 \% \mathrm{CI}-2.79$ to 7.73$)$ in urban areas and
$10.25 \%$ (95\% CI 8.25 to 12.21$)$ in rural areas. The aRR ranged from 3.32 in 2009-2010 to 5.97 in 2015-2016.

Among children aged 12-59 months, the leading causes of injury-related deaths for the period 2009-2016 were drowning, traffic injuries, suffocation, poisoning and falls. In urban areas, the rate of mortality due to traffic injuries gradually declined, with an AADR of $9.94 \%$ (95\% CI $1.37 \%$ to $17.76 \%)$. In contrast, no significant decline was observed in the rates of mortality due to drowning, suffocations, poisoning or falls. In rural areas, the rate of mortality due to drowning decreased, with an AADR of $4.41 \%$ (95\% CI 2.39\% to 6.39\%). Conversely, rates of mortality due to traffic injuries, suffocation, poisoning or falls showed no significant variation over the study period (table 3 ).

Rates of mortality due to the five leading causes of injury-related deaths were significantly higher in rural areas than in urban

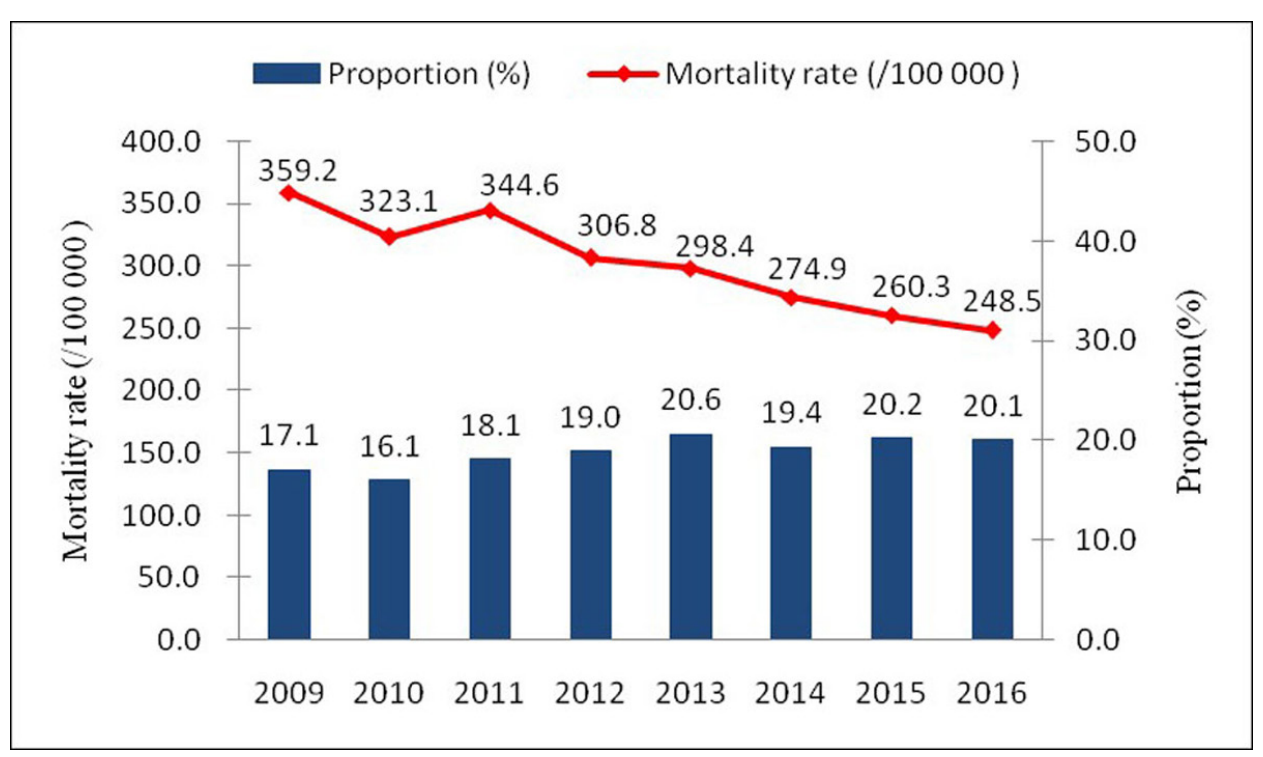

Figure 3 Mortality rate due to injury in children younger than 5 years in rural areas in China, and the proportion of injury-related deaths to allcause deaths, 2009-2016. 
Table 1 Mortality rate due to injury among infants in China, stratified by gender and urban/rural residence, 2009-2016

\begin{tabular}{|c|c|c|c|c|c|c|c|c|c|c|c|c|c|}
\hline \multirow[b]{3}{*}{ Interval } & \multicolumn{4}{|c|}{ Urban residence } & \multirow[b]{3}{*}{$\chi^{2}$} & \multirow[b]{3}{*}{$P$ values } & \multicolumn{4}{|c|}{ Rural residence } & \multirow[b]{3}{*}{$\chi^{2}$} & \multirow[b]{3}{*}{$P$ values } & \multirow[b]{3}{*}{$\operatorname{aRR}(95 \% \mathrm{Cl}) \dagger$} \\
\hline & \multicolumn{2}{|l|}{ Boys } & \multicolumn{2}{|l|}{ Girls } & & & \multicolumn{2}{|l|}{ Boys } & \multicolumn{2}{|l|}{ Girls } & & & \\
\hline & Deaths & Rate* & Deaths & Rate* & & & Deaths & Rate* & Deaths & Rate* & & & \\
\hline 2009-2010 & 33 & 20.9 & 35 & 24.7 & 0.460 & 1.498 & 345 & 142.6 & 278 & 132.7 & 0.795 & 0.373 & 6.04 (4.71 to 7.77$)$ \\
\hline 2011-2012 & 35 & 19.1 & 43 & 25.5 & 1.627 & 0.202 & 271 & 107.3 & 260 & 117.5 & 1.096 & 0.295 & 5.05 (3.98 to 6.40$)$ \\
\hline 2013-2014 & 44 & 22.0 & 29 & 15.8 & 1.921 & 0.166 & 234 & 94.2 & 215 & 96.6 & 0.072 & 0.789 & 4.96 (3.87 to 6.35$)$ \\
\hline 2015-2016 & 52 & 24.1 & 36 & 18.2 & 1.698 & 0.193 & 184 & 77.3 & 138 & 63.5 & 3.074 & 0.080 & $3.32(2.62$ to 4.20$)$ \\
\hline
\end{tabular}

Bold values indicate statistical significance.

* Rate is defined as the number of deaths due to injury per 100000 live births.

$\dagger$ aRR: Relative risk adjusted by sex, was calculated using urban residence as the reference.

.Cl, confidence interval ; aRR, adjusted relative risk.

areas, especially in the case of drowning, traffic injuries and suffocation.

\section{DISCUSSION}

Trends in injuries among children younger than 5 years in China

The mortality rate decreased obviously during 2009-2016, especially in rural areas. These decreases may reflect that China really attaches great importance to injury prevention. For example, National Program of Action for Child Development in China (2011-2020) promulgated in 2011 calls for reducing injury-related mortality in children under 18 years of age by nearly $17 \%{ }^{27}$ This outline has promoted such laws and regulations for prevention and control as 'Introducing and enforcing minimum age for drinking of alcoholic drinks', 'Wearing motorcycle and bicycle helmets', 'Using appropriate child restraints and seatbelts', 'Removing or covering water hazards', 'Product modification, ${ }^{28}$ as well as various forms of health education relating to injury prevention, including initiatives to raise awareness of self-protection among children, parents, other family members and kindergarten teachers. The outline has also pushed forward the popularisation of basic knowledge and techniques about first aid.

However, the injury-related child mortality rate in China is substantially higher than that in developed regions such as North America and Europe, ${ }^{2}$ and it remains higher than estimates in developing countries from the 2013 GBD study. ${ }^{29}$ Thus, government, medical and public health communities should keep in mind that injury remains a leading cause of child mortality.

\section{Differences in injury-related mortality rates between urban and rural areas and between boys and girls}

Among infants, we found no significant difference in injury-related mortality rates between boys and girls, either in urban or rural areas. Among children aged 12-59 months, mortality rates were higher among boys than girls in rural areas, consistent with previous studies. ${ }^{173031}$ A plausible explanation is that boys through preschool age tend to more impulsive, be more physically active and engage in higher-risk behaviour than girls. ${ }^{32} 33$

Among both age groups of children, we found that injury-related mortality rates were exceed-three times higher in rural areas than in urban areas. The possible explanation is that rural areas contain more outside spaces that increase risk of exposure to unsafe environments, poor road conditions and underdeveloped facilities, and no adequate care from caregiver who have no more energy because of farming duties or lack the information and knowledge necessary to prevent child injury. Poor rural healthcare systems also increase the risk that injuries will result in mortality.

\section{Rates of mortality associated with main causes of injury}

This study showed that suffocation, drowning and traffic injuries were top three causes of injury-related deaths among children younger than 5 years. $83.8 \%$ of suffocation-related deaths among children younger than 5 years occur in infancy, and suffocation could explain $83.0 \%$ of injury-related infant deaths, similar to previous work reports. ${ }^{3435}$ We also found that the rate of infant mortality due to suffocation declined in rural areas over the study period. This may be because parents know more about prevention and first aid, or they enjoy better access to medical services. Nevertheless, rate of mortality due to suffocation was higher in rural areas than in urban areas for infants and for children aged 12-59 months. This likely reflects the lower education level of parents in rural areas or their still-insufficient awareness about reducing risk of suffocation.

In our study, the rate of mortality due to drowning in China was lower than that in low-income and middle-income countries such as Bangladesh ${ }^{36} 37$ but higher than that in high-income

Table 2 Mortality rate due to injury in children aged 12-59 months in China, stratified by gender and urban/rural residence, 2009-2016

\begin{tabular}{|c|c|c|c|c|c|c|c|c|c|c|c|c|c|}
\hline \multirow[b]{3}{*}{ Interval } & \multicolumn{4}{|c|}{ Urban residence } & \multirow[b]{3}{*}{$\chi^{2}$} & \multirow[b]{3}{*}{$P$ values } & \multicolumn{4}{|c|}{ Rural residence } & \multirow[b]{3}{*}{$\chi^{2}$} & \multirow[b]{3}{*}{$P$ values } & \multirow[b]{3}{*}{$\operatorname{aRR}(95 \% \mathrm{Cl}) \dagger$} \\
\hline & \multicolumn{2}{|l|}{ Boys } & \multicolumn{2}{|l|}{ Girls } & & & \multicolumn{2}{|l|}{ Boys } & \multicolumn{2}{|l|}{ Girls } & & & \\
\hline & Deaths & Rate $^{*}$ & Deaths & Rate $^{*}$ & & & Deaths & Rate* $^{*}$ & Deaths & Rate* & & & \\
\hline 2009-2010 & 80 & 50.8 & 54 & 38.1 & 2.684 & 0.101 & 578 & 238.8 & 339 & 161.8 & 32.888 & $<0.001$ & 4.52 (3.77 to 5.42 ) \\
\hline 2011-2012 & 84 & 45.9 & 52 & 30.9 & 5.106 & 0.024 & 631 & 249.9 & 378 & 170.9 & 34.652 & $<0.001$ & 5.49 (4.59 to 6.57$)$ \\
\hline 2013-2014 & 87 & 43.5 & 71 & 38.7 & 0.531 & 0.466 & 572 & 230.3 & 330 & 148.3 & 41.274 & $<0.001$ & 4.61 (3.89 to 5.46$)$ \\
\hline 2015-2016 & 104 & 48.3 & 72 & 36.4 & 3.396 & 0.065 & 479 & 201.2 & 357 & 164.2 & 8.502 & 0.004 & 4.31 (3.66 to 5.07 ) \\
\hline
\end{tabular}

Bold values indicate statistical significance.

* Rate is defined as the number of deaths due to injury per 100000 live births.

taRR: Relative risk adjusted by sex, was calculated using urban residence as the reference.

$\mathrm{Cl}$, confidence interval ; aRR, adjusted relative risk. 
Table 3 Rates of mortality due to specific types of injury in children aged 12-59 months in China, stratified by urban/rural residence

\begin{tabular}{|c|c|c|c|c|c|c|c|c|c|}
\hline \multirow[b]{2}{*}{ Injury type } & \multicolumn{2}{|c|}{ 2009-2010 } & \multicolumn{2}{|c|}{ 2010-2011 } & \multicolumn{2}{|c|}{ 2012-2013 } & \multicolumn{2}{|c|}{ 2014-2015 } & \multirow[b]{2}{*}{ AADR, \% $(95 \% \mathrm{Cl})$} \\
\hline & Deaths & Rates* & Deaths & Rates* & Deaths & Rates* & Deaths & Rates* & \\
\hline \multicolumn{10}{|l|}{ Urban residence } \\
\hline Drowning & 36 & 12.0 & 42 & 11.9 & 35 & 9.2 & 55 & 13.5 & $-0.49(-7.42$ to 5.99$)$ \\
\hline Traffic injuries & 32 & 10.8 & 35 & 10.0 & 52 & 13.6 & 46 & 10.4 & 9.94 (1.37 to 17.76$)$ \\
\hline Suffocation & 29 & 9.7 & 18 & 5.1 & 21 & 5.5 & 23 & 7.2 & $6.12(-9.10$ to 19.21$)$ \\
\hline Poisoning & 8 & 2.7 & 12 & 3.6 & 4 & 0.9 & 11 & 2.8 & $-1.28(-10.05$ to 6.81$)$ \\
\hline Falls & 21 & 7.0 & 25 & 7.1 & 32 & 8.4 & 31 & 7.6 & $-3.79(-20.83$ to 10.85$)$ \\
\hline \multicolumn{10}{|l|}{ Rural residence } \\
\hline Drowning & 474 & 104.8 & 467 & 98.6 & 414 & 87.8 & 370 & 81.2 & 4.41 (2.39 to 6.39$)$ \\
\hline Traffic injuries & 197 & 43.6 & 257 & 54.2 & 241 & 51.1 & 215 & 47.3 & $3.74(-1.34$ to 8.57$)$ \\
\hline Suffocation & 79 & 17.4 & 89 & 18.8 & 68 & 14.5 & 65 & 14.4 & $5.47(-0.42$ to 11.01$)$ \\
\hline Poisoning & 64 & 14.2 & 52 & 11.0 & 47 & 9.9 & 46 & 10.2 & $-4.96(-10.59$ to 0.40$)$ \\
\hline Falls & 50 & 11.1 & 77 & 16.2 & 74 & 15.6 & 75 & 16.5 & $-0.95(-6.50$ to 4.30$)$ \\
\hline \multicolumn{10}{|l|}{$\operatorname{aRR}(95 \% \mathrm{Cl}) \dagger$} \\
\hline Drowning & \multicolumn{2}{|c|}{$8.66(6.17,12.16)$} & \multicolumn{2}{|c|}{$8.26(6.00,11.38)$} & \multicolumn{2}{|c|}{$9.58(6.79,13.58)$} & \multicolumn{2}{|c|}{$5.89(4.44,7.81)$} & - \\
\hline Traffic injuries & \multicolumn{2}{|c|}{$4.03(2.77,5.86)$} & \multicolumn{2}{|c|}{$5.43(3.81,7.73)$} & \multicolumn{2}{|c|}{$3.70(2.75,4.98)$} & \multicolumn{2}{|c|}{$4.16(3.03,4.70)$} & - \\
\hline Suffocation & \multicolumn{2}{|c|}{$1.52(1.00,2.32)$} & \multicolumn{2}{|c|}{$3.53(2.03,6.11)$} & \multicolumn{2}{|c|}{$2.56(1.54,4.25)$} & \multicolumn{2}{|c|}{$2.46(1.51,3.99)$} & - \\
\hline Poisoning & \multicolumn{2}{|c|}{$2.56(1.47,4.43)$} & \multicolumn{2}{|c|}{$1.44(0.84,2.48)$} & \multicolumn{2}{|c|}{$1.81(1.06,3.08)$} & \multicolumn{2}{|c|}{$1.46(0.89,2.40)$} & - \\
\hline Falls & \multicolumn{2}{|c|}{$1.57(0.94,2.62)$} & \multicolumn{2}{|c|}{$2.18(1.38,3.43)$} & \multicolumn{2}{|c|}{$1.82(1.20,2.78)$} & \multicolumn{2}{|c|}{$2.18(1.44,3.32)$} & - \\
\hline
\end{tabular}

Bold values indicate statistical significance.

* Rate is defined as the number of deaths due to injury per 100000 live births.

$\dagger$ aRR: Relative risk adjusted by sex, was calculated using urban residence as the reference.

$\mathrm{Cl}$, confidence interval ; $\mathrm{AADR}$, average annual decline rate; aRR, adjusted relative risk.

countries. $^{2}$ And, it also was higher than the rates in china based on 2013 data from disease surveillance points (DSPs) or from the Global Burden of Diseases project. ${ }^{38}$ These discrepancies may attributed to different sources of data: data from DSPs ${ }^{11}$ are derived from healthcare institutions and from township/ community vaccination workers, and data are representative for the general population, but it has high rates of missing data among children under 5 years of age; ${ }^{39}$ the Global Burden of Diseases data came from heterogeneous sources, including the U5CMSS and DSPs. In the present study, the rate of mortality due to drowning decreased in rural areas from 104.8 to 81.2, which may reflect the success of extensive publicity and education campaigns aimed at child caregivers and the children themselves. Due to greater exposure to natural water such as rice fields or rivers, streams and creeks, rural areas showed substantially higher rates of drowning-related mortality than urban areas.

Our results found that the rate of mortality due to traffic injuries among children aged 12-59 months in urban areas in China was lower than that in high-income countries; the corresponding rate in rural areas in China was higher than that in low-income and middle-income countries, but lower than that in Africa. ${ }^{2}$ In fact, the mortality rate decreased in urban areas from 2009 to 2016. The lower mortality rate in urban areas may reflect a 2010 law that made drunken driving, drag racing and other types of dangerous driving criminal offences. The higher mortality rate in rural areas, which may be exacerbated by the increasing number of cars and trucks and expanding road infrastructure in the country, may also reflect poor awareness of, or compliance with, traffic regulations during outdoor activities,

\section{Policy implications for injury prevention}

Our study implies that injuries are still an important public health problem affecting children's health in China, especially in rural areas. Therefore, interventions to reduce injury-related deaths among children should focus on children in rural areas, especially boys, and on more frequent types of injury in children of different age-groups. For example, interventions should be aimed at reducing suffocation-related deaths for infants. Caregivers should be taught how to prevent suffocation in babies and how to deal with it properly when suffocation occurs. On the contrary, interventions should be aimed at reducing drowning-related and traffic injuries-related deaths for children aged 12-59 months. Caregivers should be better educated about the dangers of drowning and such dangers should be better managed in water environments, including prohibiting children from particularly dangerous areas. Laws mandating the use of child safety seats should be strengthened, and measures should be taken to reduce alcohol-impaired driving. Caregivers should be educated appropriately to reduce risk of child poisoning and falls.

\section{LIMITATIONS}

The results of our study should be interpreted with caution given some limitations. First, causes of injury-related deaths relied on the recall of parents and family members, which can be biased. However, the data quality and reliability is OK, with the provincial-municipal-county level data quality control and the review of the death cases. Second, data were not collected about parental situation, family background or detailed conditions in urban or rural environments.

\section{CONCLUSION}

The injury-related mortality rate among children younger than 5 years declined in China from 2009 to 2016, but it remains higher than that in high-income countries, and urban-rural and gender disparities still exist. The rate in rural areas was higher than that in urban areas, which is attributed to the underdeveloped social economy in rural areas. And the rate in boys is higher than that in girls because boys are more impulsive and physically 
active. Suffocation remains the leading cause of mortality among infants, while drowning and traffic injuries are the leading cause of mortality among children aged 12-59 months. Accordingly, injury in children younger than 5 years remains a major public health problem. Legislation, safety education and infrastructure should be strengthened in order to reduce the injury-related deaths, and these policies and programme should be targeted to more vulnerable populations, such as rural boys and their caregivers.

\section{What is already known on the subject}

- Injury-related child mortality is a global health problem that affects developing countries like China more than developed areas.

- Injury-related mortality in China has been studied prior to 2010 or only for specific types of injury or only in local populations.

\section{What this study adds}

- We describe the epidemiology of injury-related deaths in children younger than 5 years in China for the period 2009-2016.

- Suffocation accounted for $83.0 \%$ of injury-related deaths among infants; drowning and traffic injuries were the two most frequent causes of injury-related deaths among children aged 12-59 months.

- Stark disparities still exist between the rates and types of injury-related deaths among children in urban and rural areas.

Acknowledgements We thank the countless health workers who have contributed to data collection in the U5CMSS.

Contributors $\mathrm{CH}$ and YW contributed to study design. All authors contributed to data acquisition. LCX and KW analysed the data and drafted the manuscript, which all authors revised and approved for publication.

Funding The authors have not declared a specific grant for this research from any funding agency in the public, commercial or not-for-profit sectors.

Competing interests None declared.

Patient consent Obtained.

Ethics approval Ethics Committee of West China Second University Hospital, Sichuan University.

Provenance and peer review Not commissioned; externally peer reviewed.

Open access This is an open access article distributed in accordance with the Creative Commons Attribution Non Commercial (CC BY-NC 4.0) license, which permits others to distribute, remix, adapt, build upon this work non-commercially, and license their derivative works on different terms, provided the original work is properly cited, appropriate credit is given, any changes made indicated, and the use is non-commercial. See: http://creativecommons.org/licenses/by-nc/4.0/

\section{REFERENCES}

1 Liu L, Oza S, Hogan D, et al. Global, regional, and national causes of under-5 mortality in 2000-15: an updated systematic analysis with implications for the Sustainable development goals. Lancet 2016;388:3027-35.

2 World Health Organization. World report on child injury prevention. Geneva: World Health Organization, 2008.

3 Liu L, Oza S, Hogan D, et al. Global, regional, and national causes of child mortality in 2000-13, with projections to inform post-2015 priorities: an updated systematic analysis. Lancet 2015;385:430-40.

4 He C, Liu L, Chu Y, et al. National and subnational all-cause and cause-specific child mortality in China, 1996-2015: a systematic analysis with implications for the Sustainable development goals. Lancet Glob Health 2017;5:e186-e197.
5 Cole KA, Gable S, 2002. Protecting children from unintentional injuries. Springfield, USA: University of Missouri. https://extension2.missouri.edu/GH6026 (accessed Mar 2018).

6 The Central Committee of the Communist Party of China, The State Council of the People's Republic of China. 'Healthy China 2030 planning outline', 2016.

7 Hong J, Lee B, Ha EH, et al. Parental socioeconomic status and unintentional injury deaths in early childhood: consideration of injury mechanisms, age at death, and gender. Accid Anal Prev 2010:42:313-9.

8 Suzuki H, Hikiji W, Tanifuji T, et al. Child deaths from injury in the special wards of Tokyo, Japan (2006-2010): a descriptive study. J Epidemiol 2014;24:178-82.

9 Philippakis A, Hemenway D, Alexe DM, et al. A quantification of preventable unintentional childhood injury mortality in the United States. Inj Prev 2004:10:79-82.

10 Jagnoor J, Suraweera W, Keay L, et al. Unintentional injury mortality in India, 2005: nationally representative mortality survey of 1.1 million homes. BMC Public Health 2012;12:487.

11 Wang L, Cheng X, Yin P, et al. Unintentional drowning mortality in China, 2006-2013. Inj Prev 2019;25:47-51.

12 Wang L, Wu Y, Yin P, et al. Poisoning deaths in China, 2006-2016. Bull World Health Organ 2018;96:314-26

13 Cheng $\mathrm{P}$, Yin $\mathrm{P}$, Ning $\mathrm{P}$, et al. Trends in traumatic brain injury mortality in China, 20062013: a population-based longitudinal study. PLoS Med 2017;14:e1002332.

14 Zhou M, Hu G, Wang L, et al. Bicyclist mortality between 2006 and 2010 in China: findings from national Disease Surveillance Points (DSP) data. Inj Prev 2014;20:7-10.

15 Ma S, Hu GQ, Li QF, Ms S, GQ H, QF L, et al. Pedestrian mortality between 2006 and 2010 in China: findings from non-police reported data. Biomed Environ SCi 2013;26:853-6.

16 Ning P, Cheng X, Zhang L, et al. [Injury mortality in China, from 1990 to 2010]. Zhonghua Liu Xing Bing Xue Za Zhi 2015;36:1387-90.

17 Wang Y, He C, Li X, et al. Nationwide study of injury-related deaths among children aged 1-4 years in China, 2000-2008. J Paediatr Child Health 2014;50:E94-101.

18 Ozanne-Smith J, Li Q. A social change perspective on injury prevention in China. Inj Prev 2018;24(Suppl 1):i25-31.

19 Feng XL, Guo S, Hipgrave D, et al. China's facility-based birth strategy and neonatal mortality: a population-based epidemiological study. Lancet 2011;378:1493-500.

20 Wang YP, Miao L, Dai L, et al. Mortality rate for children under 5 years of age in China from 1996 to 2006. Public Health 2011;125:301-7.

21 He C, Kang L, Miao L, et al. Pneumonia mortality among children under 5 in china from 1996 to 2013: an analysis from national surveillance system. PLoS One 2015;10:e0133620.

22 Cui H, Kang L, Li Q. Under-5-years child mortality due to congenital anomalies: a retrospective study in urban and rural China in 1996-2013. Am J Prev Med 2015;50:663-71.

23 World Health Organization. International statistics classification of diseases and related health problem (ICD-10), 10th rev. Geneva: World Health Organization, 1993.

24 Flavin MP, Dostaler SM, Simpson K, et al. Stages of development and injury patterns in the early years: a population-based analysis. BMC Public Health 2006;6:187.

25 Rudan I, Chan KY, Zhang JS, et al. Causes of deaths in children younger than 5 years in China in 2008. Lancet 2010;375:1083-9.

26 Bhalla K, Hu G, Bake TD. Injuries among children: an unrecognized threat in low- and middle-income countries. 140st APHA Annual Meeting and Exposition 2012, 2012.

27 The state council of the People's Republic of China. National program of action for child development in China 2011

28 Li L, Scherpbier R, Wu J, et al. Legislation coverage for child injury prevention in China. Bull World Health Organ 2015;93:169-75.

29 Huang Y, Wu Y, Schwebel DC, et al. Disparities in under-five child injury mortality between developing and developed countries: 1990-2013. Int J Environ Res Public Health 2016;13:653.

30 Pant PR, Towner E, Ellis M, et al. Epidemiology of unintentional child injuries in the makwanpur district of nepal: a household survey. Int I Environ Res Public Health 2015;12:15118-28.

31 Hu GQ, Zhu SL, Wang QQ, et al. [An epidemiological survey on the incidence of non-fatal injury and influencing factors among children under 5 years old in China]. Zhonghua Liu Xing Bing Xue Za Zhi 2011;32:773-6.

32 Ma J, Guo X, Xu A, et al. Epidemiological analysis of injury in shandong province, China. BMC Public Health 2008;8:122.

33 Runyan CW, Casteel C, Perkis D, et al. Unintentional injuries in the home in the United States Part I: mortality. Am J Prev Med 2005;28:73-9.

34 Pan SY, Ugnat AM, Semenciw R, et al. Trends in childhood injury mortality in Canada, 1979-2002. Inj Prev 2006:12:155-60.

35 Tomashek KM, Hsia J, Iyasu S. Trends in postneonatal mortality attributable to injury, United States, 1988-1998. Pediatrics 2003:111):1219-25.

36 World Health Organization. Global report on drowning. Geneva: World Health Organization, 2014

37 Rahman A, Alonge O, Bhuiyan AA, et al. Epidemiology of Drowning in Bangladesh: an update. Int J Environ Res Public Health 2017;14:E488.

38 Global Burden of Disease Collaborative Network, Global Burden of Disease Study 2016 (GBD 2016) Results, 2017. In. Seattle, United States: Institute for Health Metrics 
and Evaluation (IHME). http://ghdx.healthdata.org/gbd-results-tool (accessed Aug 2018).
39 Yin Z, Wu J, Luo J, et al. Burden and trend analysis of injury mortality in China among children aged 0-14 years from 2004 to 2011. BMJ Open 2015;5:e007307. 